của đối tượng nghiên cứu có điểm trung bình khá cao $(60,4 ; 63,8)$.

Các nghiên cứu trên những đối tượng khác nhau cho kết quả cũng khác nhau: Nguyễn Thành Lam và cộng sự (2019) [2] nghiên cứu trên 327 người bệnh ung thư điều trị taii Trung tâm Ung bướu Thái Nguyên cho thấy điểm trung bình của các triệu chứng hay gặp là: đau $(63,3)$, mệt mỏi $(58,5)$, chán ăn $(49,6)$, mất ngủ $(47,8)$, khó khăn tài chính $(77,5)$. Tuy vậy, nhìn chung trung bình sức khỏe tổng quát của người bệnh ung thư đều tương đối thấp, các triệu chứng đau, mệt mỏi, chán ăn, mất ngủ đều hay gặp với điểm trung bình tương đối cao, ngược lại các triệu chứng ít gặp như tiêu chảy, táo bón, buồn nôn, nôn có điểm trung bình thấp.

\section{KẾT LUẬN}

Sau xạ trị điểm trung bình một số lĩnh vực chức năng cao hơn thời điểm trước xạ trị nhứ: cảm xúc $(72,8 ; 76,7)$, nhận thức $(72,0 ; 77,2)$, còn lînh vực "Chức năng hoạt động" không thay đổi đáng kể $(31,7 ; 31,2)$.

Chất lượng cuộc sống chung ở mức trung bình cả 2 thời điểm nghiên cứu là 54,0 điểm.

Lĩnh vực triệu chứng của người bệnh UTPKTBN giai đoạn III kể cả trước và sau xạ trị thường gặp có điểm trung bình là: mệt mỏi $(68,2 ; 65,8)$, đau $(54,4 ; 43,6)$, chán ăn $(53,0$; $50,2)$, mất ngủ $(52,5 ; 28,5)$ và khó thở $(31,7$; $25,9)$. Các triệu chứng buồn nôn, táo bón và tiêu chảy ít gặp với điểm trung bình dưới 20 điểm cả 2 thời điểm. Vấn đề khó khăn tài chính của đối tượng nghiên cứu ở mức trung bình $(60,4 ; 63,8)$.

\section{TÀI LIẸU THAM KHẢO}

1. Globocan 2020. https://gco.iarc.fr/ today/data/ factsheets/ populations/900-world-fact-sheets.

2. Nguyễn Thành Lam và cộng sự (2019), "Tình trạng đau và chất lượng cuộ́c sống của bệnh nhân ung thư điêu trị tại Trung tâm Ung bướu Thái Nguyên từ tháng 1- 6 năm 2019". Tạp chí thần kinh học Việt Nam số 28.

3. Phạm Cẩm Phương và Mai Trọng Khoa (2016), "Đánh giá chẩt lượng cuộc sống của bệnh nhân ung thư phổi không tế bào nhỏ được điêu trị thuốc ức chế TIROSINE KINASE tại Bệnh viện Bạch Mai". Tạp chí Y - Dược hơc quân sự số 1.

4. Nguyến Thanh Mai (Đề tài cơ sở 2019), "Chất lượng cuộc sống và các yễu tố liên quan của người bểnh ung thư phổi sau phẫu thuật"

5. Phạm Thị Hoàng Anh, Ngự̂̃n Mạnh Quốc, Nguyễn Bá Đức, Nguyễn Chấn Hùng (2001), "Tinh hình bệnh ung thư ở Việt Nam năm 2000". Tạp chí thông tin Y dược số 2 .

6. Trưan Bảo Ngọc, Bùi Diệu, Nguyễn Tuyết Mai (2012). Chất lươơng cuộc sống 71 bệnh nhân ung thư đâu cổ giai đoạn muộn sau hóa trị tuân tự sử dụng bộ câu hỏi EORTC QLQQ C-30 và QLQ-H\&Nं35. Tạp chí Ung thư hooc Viêt Nam.

7. Bừi Vũ Bình, Đố Thị Ânh, Dương Tiến Đỉnh và các cộng sự. (2015), Khảo sát chất lượng cuộc sống của bệnh nhân ung thư và một số yểu tố ảnh hưởng tại Bệnh viện Đại học Y Hà Nội năm 2015, Báo cáo Hội nghị khoà học chào mừng 65 năm truyền thống Bệnh viện Quần y 103, Hội nghị Khoa học điêu dưỡng, Hà Nội.

8. Bergman B, Aaronson NK, Ahmedzai $S$ et al. The EORTC QLQ-LC13: a modular supplement to the EORTC Core Quality of Life Questionnaire (QLQ-C30) for use in lung cancer clinical trials. EORTC Study Group on Quality of Life. Eur J Cancer. 1994, 30A (5), pp.635-642. 4

\title{
KẾT QUẢ ĐIỀU TRỊ DỰ PHÒNG HUYẾT KHỐI TĨNH MẠCH CỦA WARFARIN VÀ RIVAROXABAN TRONG VÀ SAU PHẪU THUÂTT
}

\section{TÓM TẮT}

Mục tiêu: Đánh giá kết quả điều trị dự phòng huyết khối tĩnh mạch của warfarin và rivaroxaban trong và sau phẫu thuật. Đối tượng và phương pháp nghiên cứu: Hồi cứu 10870 người bệnh phẫu thuật >18 tuổi từ 1/1/2017 đến 31/9/2018 được điều trị chống đông bằng warfarin hoặc rivaroxaban. Trong

\footnotetext{
${ }^{1}$ Trường Đại học Y Hà Nội

${ }^{2}$ Bệnh viện Đại học Y Hà Nội

Chịu trách nhiệm chính: Bùi Mỹ Hạnh

Email: buimyhanh@hmu.edu.vn

Ngày nhận bài: 13.9.2021

Ngày phản biện khoa học: 11.11.2021

Ngày duyệt bài: 17.11.2021
}

$$
\text { Bùi Mỹ Hạnh", }{ }^{1,2} \text { Lê Văn Tú }{ }^{1,2}
$$

đó 4191 NB dự phòng bằng warfarin và 6679 NB dự phòng bằng rivaroxaban. Kết quả nghiên cứu: Trong đợt nằm viện sau phẫu thuật có $37 / 6679$ $(0,6 \%)$ NB điều trị rivaroxaban và $52 / 4191(1,2 \%)$ NB điều trị warfarin xuất hiện HKTM (bao gồm cà tắc mach phổi và huyết khối tĩnh mạch chi dưới). Đồng thời sau ra viện 90 ngày có $36 / 6679(0,5 \%)$ NB dự phòng với rivaroxaban xuất hiên HKTM ít hơn 51/4191 $(1,2 \%)$ NB bệnh dự phòng với warfarin. Tỷ lệ có biến chứng xuất huyết ở nhóm dự phòng với warfarin nhiều hơn so với nhóm dự phòng với rivaroxaban $(7,3 \%$ và $4,2 \%)$ có ý nghĩa thống $k e ̂(p<0,05)$. Trong số biến chứng xuất huyết xuất hiện phần lớn là nhồi máu não $(3,7 \%$ trong nhóm dự phò̀ng với rivaroxaban và $5,9 \%$ trong nhóm dự phòng với warfarin) ngoài ra có xuất huyết tiêu hóa và một số xuất huyết khác. Kết luận: Rivaroxaban làm giảm tỷ lệ tái phát HKTM và khổng 
làm tăng nguy cơ xuất huyết ở BN sau phẫu thuật so với warfarin, sự khác biệt có ý nghĩa thống kê.

Tư khóa: rivaroxaban, warfarin, huyết khối tĩnh mạch

\section{SUMMARY}

\section{THE OUTCOMES OF VENOUS} THROMBOEMBOLISM PROPHYLAXIS USING RIVAROXABAN VERSUS WARFARIN DURING AND AFTER SURGERY

Objectives: To evaluate the treatment outcome of VTE prophylaxis with warfarin and rivaroxaban during and after surgery. Subjects and methods: A retrospective review of 10870 surgical patients aged $>18$ years from January 1, 2017 to September 31, 2018 who received anticoagulation with warfarin or rivaroxaban. Of these, 4191 patients were prevented by warfarin and 6679 were prevented by rivaroxaban. Result: During the postoperative hospital stay, there were $37 / 6679(0.6 \%)$ patients treated with rivaroxaban and 52/4191 (1.2\%) patients treated with warfarin being diagnosed as having VTE (including pulmonary embolism and lower extremities deep venous thrombosis). At the same time, after 90 days of discharge, $36 / 6679(0.5 \%)$ patients who received rivaroxaban prophylaxis developed VTE, which is less than $51 / 4191(1.2 \%)$ patients with warfarin prophylaxis. The rate of bleeding complications in the warfarin prophylactic group was higher than in the rivaroxaban prophylaxis group $(7.3 \%$ and $4.2 \%)$ with statistical significance $(p<0.05)$. Among hemorrhagic complications, the majority were cerebral infarction $3.7 \%$ in the prophylactic group with rivaroxaban and $5.9 \%$ in the prophylactic group with warfarin) in addition to gastrointestinal bleeding and some other bleeding complications. Conclusion: Rivaroxaban reduced the rate of VTE recurrence and did not increase the risk of bleeding complication in postoperative patients in comparison with warfarin, the difference was statistically significant.

Keyword: rivaroxaban, warfarin, venous thromboembolism

\section{I. ĐĂT VẤN ĐỀ}

Huyết khối tĩnh mạch bao gồm huyết khối tĩnh mạch sâu và tắc mạch phổi luôn là mối đe dọa với người bệnh phẫu thuật [1]. Tại Việt Nam, tỉ lệ mắc HKTM trong và sau phẫu thuật theo tác giả Bùi Mỹ Hanh năm 2019 là 0,1\% [2]. Tuy nhiên HKTM có thể phòng ngừa bằng dự phòng thuốc chống đông cũng như các biện pháp cơ học khác hỗ trợ cho người bênh. Với sự ra đời của nhiều thuốc kháng đông thế hê mới, việc lựa chọn thuốc hiệu quả theo các khuyến cáo mới và phù hợp cho từng người bệnh, hạn chế nguy cơ tái mắc HKTM và xuất huyết còn là một thách thức. Để không ngừng nâng cao chất lượng và kết quả điều trị chúng tôi thực hiện nghiên cứu này với mục tiêu "Đánh giá kêt quả điều trị dự phòng huyết khối tĩnh mạch của warfarin và rivaroxaban của người bệnh trong và sau phẫu thuật.".

\section{II. ĐỐI TƯƠNG VÀ PHƯƠNG PHÁP NGHIÊN CỨU 1. Đối tượng nghiên cứu}

Tiêu chuẩn lựa chon. Người bệnh từ 18 tuổi trở lên từ 1/1/2017 đến 31/9/2018 được thực hiên môt trong bảy chuyên khoa phẫu thuật bao gồm: (1) Phẫu thuât thần kinh cột sống; (2) Phẫu thuật tim; (3) Phẫu thuât mach; (4) Phẫu thuật tiết niệu; (5) Phẫu thuật tiêu hóa; (6) Phẫu thuật chấn thương chỉnh hình; (7) Phẩu thuật tao hình. Sau khi được chẩn đoán xác định HKTMS bằng siêu âm doppler tĩnh mach hoặc chẩn đoán xác định TMP bằng chụp cắt lớp vi tính. Dữ liệu trích xuất bệnh án theo yêu câu định dang chuyển đổi thống nhất lên cổng bảo hiểm từ $1 / 1 / 2017$ cho đến ngày $31 / 9 / 2018$ [3] được chỉ định điều trị chống đông dự phòng bằng warfarin hoăc rivaroxaban

Tiêu chuânn loai trừ. Người bênh đã trải qua phẫu thuât loai bỏ huyết khối, sử dụng lưới lọc tĩnh mạch chủ; hoặc nếu có bất kỳ chống chỉ định nào liên quan đến sử dụng thuốc kháng Vitamin $\mathrm{K}$.

\section{Phương pháp}

a. Thiết kến nghiên cứu: Nghiên cứu hồi cứu

b. Cỡ mẫu và chọn mấu. Áp dụng phương pháp chọn mẫu thuận tiên thu được 10870 NB phẫu thuât đạt tiêu chuẩn lựa chọn chia làm 2 nhóm: Nhóm 4191 dự phòng bằng warfarin và nhóm 6679 NB dự phòng bằng rivaroxaban.

c. Tiêu chẩn chẩn đoán HKTM. NB được chẩn đoán huyết khối tắc mạch phổi (I26), bệnh viêm tĩnh mạch và tắc tĩnh mạch (I80), huyết khối tĩnh mạch cửa (I81), thuyên tắc và huyết khối tĩnh mạch khác (I82) theo Hướng dẫn chẩn đoán và điều trị Hội huyết học Hoa Kỳ [4].

d. Biến số. Tính hiệu quả được đánh giá qua tỉ lệ mắc HKTMS, TMP, HKTM và tính an toàn được đánh giá bằng tî lệ nhồi máu não, xuất huyết tiêu hóa và xuất huyết khác sau điều trị bằng warfarin và riboxaban. Các số liệu được xác định tại đợt nằm viện sau phẫu thuật, sau ra viện 90 ngày.

3. Xử lý số liệu: Dữ liệu được xử lý bằng phần mềm thống kề stata 16.0. Mố tả dưới dạng tân số tỷ lệ \%, sử dụng kiểm định Chi bình phương và Fisher test để đo lường sự khác biệt trong các mối liên hêe của kết quả nghiên cứu. Các kết quả có ý nghĩa thống kê khi p<0,05.

4. Đạo đức nghiên cứu. Nghiên cứu được triển khai nhằm mục đích nâng cao chất lượng khám chữa bệnh. Thông tin người bệnh hoàn 
toàn được bí mật và tuân thủ các quy định thông tư 45/2017/TT-BYT. Được sự chấp thuận của Hội

\section{KẾT QUẢ NGHIÊN CỨU}

\section{Bảng 3. 2. Đặc điểm chung của 2 nhóm nghiên cứu}

\begin{tabular}{|c|c|c|c|c|}
\hline \multicolumn{2}{|c|}{ Đặc điếm } & \multirow{3}{*}{$\begin{array}{c}\text { Rivaroxaban } \\
\mathbf{6 6 7 9}(\mathbf{1 0 0 \%}) \\
644(9,6 \%)\end{array}$} & \multirow{3}{*}{$\begin{array}{c}\text { Warfarin } \\
\mathbf{4 1 9 1}(\mathbf{1 0 0} \%) \\
692(16,5 \%)\end{array}$} & \multirow[t]{2}{*}{ p-value } \\
\hline & $\mathbf{N}$ & & & \\
\hline \multirow{4}{*}{$\begin{array}{l}\text { Nhóm } \\
\text { tuổi }\end{array}$} & $18-40$ & & & \multirow{4}{*}{$<0,001$} \\
\hline & $41-60$ & $2110(31,6 \%)$ & $2115(50,5 \%)$ & \\
\hline & $61-74$ & $1894(28,4 \%)$ & $1020(24,3 \%)$ & \\
\hline & $>74$ & $2031(30,4 \%)$ & $364(8,7 \%)$ & \\
\hline \multirow{2}{*}{ Giới tính } & Nam & $3159(47,3 \%)$ & $1926(46,0 \%)$ & \multirow{2}{*}{0,17} \\
\hline & Nũ̃ & $3520(52,7 \%)$ & $2265(54,0 \%)$ & \\
\hline \multirow{7}{*}{$\begin{array}{l}\text { Loại phẫu } \\
\text { thuật }\end{array}$} & Thần kinh, cột sống & $55(0,8 \%)$ & $174(4,2 \%)$ & \multirow{7}{*}{$<0,001$} \\
\hline & Tim ngực & $20(0,3 \%)$ & $2786(66,5 \%)$ & \\
\hline & Mạch máu & $115(1,7 \%)$ & $453(10,8 \%)$ & \\
\hline & Dạ dày, ruột & $116(1,7 \%)$ & $382(9,1 \%)$ & \\
\hline & Thận tiết niệu & $40(0,6 \%)$ & $79(1,9 \%)$ & \\
\hline & Phâu thuật chỉnh hình & $6322(94,7 \%)$ & $297(7,1 \%)$ & \\
\hline & Tạo hình & $11(0,2 \%)$ & $20(0,5 \%)$ & \\
\hline \multirow{6}{*}{$\begin{array}{l}\text { Nhóm } \\
\text { điểm } \\
\text { caprini }\end{array}$} & Nhập viện cấp cứu & $1933(28,9 \%)$ & $715(17,1 \%)$ & 0,048 \\
\hline & $0-<2$ & $7(0,1 \%)$ & $11(0,3 \%)$ & \multirow{5}{*}{$<0,001$} \\
\hline & $2-4$ & $810(12,1 \%)$ & $2817(67,2 \%)$ & \\
\hline & $5-6$ & $440(6,6 \%)$ & $897(21,4 \%)$ & \\
\hline & $7-8$ & $2080(31,1 \%)$ & $165(3,9 \%)$ & \\
\hline & $>8$ & $3342(50,0 \%)$ & $301(7,2 \%)$ & \\
\hline \multicolumn{2}{|r|}{ Suy tim } & $143(2,1 \%)$ & $1937(46,2 \%)$ & \multirow{2}{*}{$\begin{array}{l}<0,001 \\
<0001\end{array}$} \\
\hline \multirow{2}{*}{\multicolumn{2}{|c|}{$\begin{array}{l}\text { Mạch máu ngoại vi } \\
\text { Liệt nứa người }\end{array}$}} & $42(0,6 \%)$ & $91(2,2 \%)$ & \\
\hline & & $15(0,2 \%)$ & $22(0,5 \%)$ & $\begin{array}{c}<0,001 \\
0,009 \\
\end{array}$ \\
\hline \multicolumn{2}{|r|}{ Khớp } & $185(2,8 \%)$ & $51(1,2 \%)$ & \multirow{2}{*}{$\begin{array}{l}<0,001 \\
<0,001\end{array}$} \\
\hline \multicolumn{2}{|r|}{ Loét dạ dày } & $702(10,5 \%)$ & $602(14,4 \%)$ & \\
\hline \multicolumn{2}{|r|}{ Tiểu đường } & $601(9,0 \%)$ & $279(6,7 \%)$ & \multirow{2}{*}{$\begin{array}{c}<0,001 \\
0,23\end{array}$} \\
\hline & iến chứng tiếu đường & $8(0,1 \%)$ & $2(0,04 \%)$ & \\
\hline & Ung thu' & $206(3,1 \%)$ & $144(3,4 \%)$ & 0,31 \\
\hline & Ung thư di căn & $8(0,1 \%)$ & $7(0,2 \%)$ & 0,52 \\
\hline & Bệnh gan nhẹ & $193(2,9 \%)$ & $88(2,1 \%)$ & 0,012 \\
\hline & Suy xơ gan & $6(0,1 \%)$ & $7(0,2 \%)$ & 0,26 \\
\hline & Suy thận mạn & $63(0,9 \%)$ & $86(2,1 \%)$ & $<0,001$ \\
\hline & Sa sút trí tuệ & $9(0,1 \%)$ & $3(0,1 \%)$ & 0,33 \\
\hline & Thiếu máu mao mạch & $36(0,5 \%)$ & $31(0,7 \%)$ & 0,19 \\
\hline & Sút cân & $68(1,0 \%)$ & $45(1,1 \%)$ & 0,78 \\
\hline & RL nước và điện giải & $24(0,4 \%)$ & $37(0,9 \%)$ & $<0,001$ \\
\hline & U lympho & $9(0,1 \%)$ & $5(0,1 \%)$ & 0,83 \\
\hline & Suy giáp & $19(0,3 \%)$ & $9(0,2 \%)$ & 0,49 \\
\hline & Thiếu máu tủy & $40(0,6 \%)$ & $37(0,9 \%)$ & 0,086 \\
\hline & Loạn nhịp tim & $112(1,7 \%)$ & $932(22,2 \%)$ & $<0,001$ \\
\hline & Van tim & $24(0,4 \%)$ & $1985(47,4 \%)$ & $<0,001$ \\
\hline & Mạch máu phối & $7(0,1 \%)$ & $49(1,2 \%)$ & $<0,001$ \\
\hline & Tằng huyết áp & $1435(21,5 \%)$ & $1039(24,8 \%)$ & $<0,001$ \\
\hline & ến chứng tăng huyết áp & $31(0,5 \%)$ & $47(1,1 \%)$ & $<0,001$ \\
\hline & Bệnh đông máu & $10(0,1 \%)$ & $28(0,7 \%)$ & $<0,001$ \\
\hline & Bênh phối man tính & $158(2,4 \%)$ & $169(4,0 \%)$ & $<0,001$ \\
\hline & Bệnh tuần hoàn não & $311(4,7 \%)$ & $354(8,4 \%)$ & $<0,001$ \\
\hline & Tiền sư PE & $3(0,04 \%)$ & $1(0,02 \%)$ & 0,58 \\
\hline & Tiền sứ DVT & $22(0,3 \%)$ & $34(0,8 \%)$ & $<0,001$ \\
\hline & Tiền sử VTE & $25(0,4 \%)$ & $37(0,9 \%)$ & $<0,001$ \\
\hline
\end{tabular}

đồng đạo đức trường Đại học $Y$ Hà Nội. Số quyết định 67/HDDDDHYHN ngày 24 tháng 3 năm 2017. 
Nhận xét: Có 17 trong 27 bệnh mắc trước phẫu thuật có sự khác biệt có ý nghĩa thống kê $(p<0,05)$ ở 2 nhóm người bệnh dự phòng với Rivaroxaban và Warfarin bao gồm suy tim, mạch máu ngoại vi, liệt nửa người, khớp, loét dạ dày, tiểu đường, bệnh gan nhẹ, suy thận mạn tính, rối loạn nước và điện giải, loạn nhịp tim, mạch máu phổi, tăng huyểt áp, biến chứng tăng huyết áp, bệnh đông máu, bệnh phổi tắc nghẽn mạn tính, bệnh tuần hoàn nã̃o. Trong đó các bệnh lý về tim là có sự khác biệt nhiều nhất giữa 2 nhóm, trong số những người bệnh dự phòng với wafarin $47,4 \%$ có bệnh van tim và $46,2 \%$ có suy tim và $22,2 \%$ có loạn nhịp tim, trong khi tỷ lệ này trong nhóm người bệnh dự phòng với rivaroxaban lần lượt là $0,4 \%, 2,1 \%$ và $1,7 \%$. Ngoài ra tăng huyết áp và loét dạ dày cũng là 2 bệnh phổ biến hơn so với những bệnh còn lại (có $21,5 \%$ và $24,8 \%$ có tăng huyết áp lần lượt ở nhóm dự phòng rivaroxaban và nhóm dự phòng warfarin; $10,5 \%$ và $14,4 \%)$.

\section{Bảng 3.3. Tính hiệu quả của wafarin và rivaroxaban ở NB phẫu thuật}

\begin{tabular}{|c|c|c|c|}
\hline Tính hiệu quả & $\begin{array}{c}\text { Rivaroxaban } \\
\mathbf{6 6 7 9 ( 1 0 0 \% )}\end{array}$ & $\begin{array}{c}\text { Warfarin } \\
\mathbf{4 1 9 1}(\mathbf{1 0 0} \%)\end{array}$ & p-value \\
\hline HKTM trong đợt nằm viện phẫu thuật & $37(0,6 \%)$ & $52(1,2 \%)$ & $<0.001$ \\
\hline HKTM sau 90 ngày ra viện & $36(0,5 \%)$ & $51(1,2 \%)$ & $<0.001$ \\
\hline
\end{tabular}

Nhận xét: Sau phấu thuật có $37 / 6679$ (0.6\%) người bệnh xuất hiện biến chứng huyết khối ở các nhóm dự phòng với rivaroxaban và warfarin là $52 / 4191(1,2 \%)$. Theo dõi tại thời điểm sau ra viện 90 ngày có $36 / 6679(0,5 \%)$ người bệnh dự phòng với rivaroxaban xuất hiện biến chứng huyết khối ít hơn 51/4191 (1,2\%) người bệnh dự phòng với warfarin. Kết quả trên cho thấy hầu hết người bệnh xuất hiện huyết khối ở thời điểm 90 ngày sau ra viện ở cả 2 nhóm. Sự khác biệt có ý nghĩa thống kê với $p<0,05$.

Bảng 3.4. Tính an toàn của wafarin và rivaroxaban

\begin{tabular}{|c|c|c|c|}
\hline Tính an toàn & $\begin{array}{c}\text { Rivaroxaban } \\
\mathbf{6 6 7 9}(\mathbf{1 0 0} \%)\end{array}$ & $\begin{array}{c}\text { Warfarin } \\
\mathbf{4 1 9 1}(\mathbf{1 0 0} \%)\end{array}$ & p-value \\
\hline Nhồi máu não & $246(3,7 \%)$ & $246(5,9 \%)$ & 0,005 \\
\hline Xuất huyết tiêu hóa & $17(0,3 \%)$ & $11(0,3 \%)$ & $<0,001$ \\
\hline Xuất huyết khác & $16(0,2 \%)$ & $43(1,03 \%)$ & $<0,001$ \\
\hline Nhồi máu não+ xuất huyết tiêu hóa & $2(0,03 \%)$ & $1(0,02 \%)$ & $<0,001$ \\
\hline Nhồi máu não và xuất huyết khác & $2(0,03 \%)$ & $6(0,1 \%)$ & $<0,001$ \\
\hline Biến chứng xuất huyết & $283(4,2 \%)$ & $307(7,3 \%)$ & $<0,001$ \\
\hline
\end{tabular}

Nhận xét: Tỷ lệ người bệnh có biến chứng xuất huyết trong 2 nhóm sử dụng thuốc dự phòng khác nhau có ý nghĩa thống kê, tỷ lệ người bệnh có biến chứng xuất huyết ở nhóm dự phòng với warfarin nhiều hơn so với nhóm dự phòng với rivaroxaban (7,3\% và $4,2 \%)$. Trong số biến chứng xuất huyết xuất hiện phần lớn là nhồi máu não $(3,7 \%$ trong nhóm dự phòng với rivaroxaban và $5,9 \%$ trong nhóm dự phòng với warfarin) ngoài ra có xuất huyết tiêu hóa và một số xuất huyết khác. Sự khác biệt có ý nghĩa thống kê với $p<0,05$.

\section{BÀN LUÂN}

Đối với các bác sĩ phẫu thuật, một thách thức cấp thiết là làm thế nào để sử dụng thuốc chống đông máu để dự phòng HKTM hiệu quả mà không có nguy cơ gặp các biến chứng nặng khác như xuất huyết não, nhồi máu não. Điều này cần được xác định thông qua đánh giá tính an toàn và hiệu quả [5].

Tính hiệu quả. Rivaroxaban có tác dụng chống đông máu mạnh trong điều trị dự phòng
HKTM sau phẫu thuật với vai trò ức chế yếu tố Xa có tính chọn lọc cao, có thể ức chế cạnh tranh sự tự do và gắn kết của yếu tố Xa cũng như hoạt động của prothrombin [1]. Trong nghiên cứu của chúng tôi sau phẫu thuật có $37 / 6679(0,6 \%)$ và $52 / 4191(1,2 \%)$ người bênhxuất hiện biến chứng huyết khối lần lượt ở các nhóm dự phòng với rivaroxaban và dự phòng với warfarin. Tại thời điểm sau ra viện 90 ngày có $36 / 6679(0,5 \%)$ người bênh dư phòng với rivaroxaban xuất hiên biến chứng huyết khối ít hơn 51/4191 (1,2\%) người bệnh dự phòng với warfarin. Kết quả trên cho thấy hầu hết người bệnh xuất hiện huyết khối ở thời điểm 90 ngày sau ra viện ở cả 2 nhóm. Một nghiên cứu tổng quan của Lyon C năm 2017 cho thấy sau 90 ngày tỉ lệ NB tái phát HKTM khi dùng rivaroxaban giảm so với nhóm NB dùng warfarin với $\mathrm{OR}=0,69 ; \mathrm{KTC} 95 \%, 0,48$ đến 0,99 [7]. Các nhà điều tra SWIVTER đã thực hiện phân tích hồi cứu về dữ liệu nhận thấy nguy cơ HKTM tái phát ở nhóm NB dự phòng bằng rivaroxaban 
$(1,2 \%)$ thấp hơn so với nhóm warfarin $(2,1 \%)$ với $\mathrm{HR}=0,55, \mathrm{KTC} 95 \%=0,18-1,65)[6]$.

Tính an toàn. Biến chứng xuất huyết là những tác dụng không mong muốn được báo cáo phổ biến nhất trong các thử nghiệm lâm sàng về thuốc chống đông. Xuất huyết trong nghiên cứu của chúng tôi bao gồm chảy máu não, chảy máu sau phúc mạc và bất kỳ tình trạng chảy máu nào dẫn tới tử vong, nhập viện, hoặc phải truyền máu. Một nghiên cứu tổng quan của Sean $T$ năm 2012 đã chỉ ra rằng rivaroxaban có hiệu quả dự phòng HKTM cao hơn mà không làm tăng nguy cơ xuất huyết [7]. Nghiên cứu của chúng tôi chỉ ra tỷ lệ người bệnh có biến chứng xuất huyết trong 2 nhóm sử dụng thuốc dự phòng khác nhau có ý nghĩa thống kê, tỷ lệ người bệnh có biến chứng xuất huyết ở nhóm dự phòng với warfarin nhiều hơn so với nhóm dư phòng với rivaroxaban $(7.3 \%$ và 4.2\%). Trong số biến chứng xuất huyết xuất hiện phần lớn là nhồi máu não $(3.7 \%$ trong nhóm dự phòng với rivaroxaban và $5.9 \%$ trong nhóm dự phòng với warfarin) ngoài ra có xuất huyết tiểu hóa và một số xuất huyết khác. Sự khác biệt có ý nghĩa thống kê với $p<0,05$. Kết quả nghiên cứu của chúng tôi phù hợp với nghiên cứu Craig IC năm 2018 về hiệu quả điều trị dự phòng HKTM của warfarin và rivaroxaban trên 6869 NB cho thấy tỷ lệ xuất huyết tiêu hóa ở nhóm warfarin $(1,1 \%)$ cao hơn nhóm rivaroxaban $(0,9 \%)$, tỷ lệ chảy máu não ở nhóm warfarin $(0,2 \%)$ cao hơn nhóm rivaroxaban $(0,1 \%)$ [8]. Nghiên cứu của Nils Kucher năm 2016 lại cho thấy nguy cơ chảy máu lớn ở cái 2 nhóm tương đương nhau (0,5\% so với 0,5\%; HR $=1,00$, KTC $95 \%=0,14-7,07)$ [5]. Rivaroxaban là một phương pháp điều trị bằng thuốc uống đơn lẻ, cung cấp một giải pháp thay thế an toàn cho warfarin với ít tương tác thuốc hơn và tính dược lý dễ đoán hơn, giúp giảm thiểu nhu cầu giám sát trong phòng thí nghiệm về tác dụng chống đông máu và điều chỉnh liều thường xuyên.

Điểm mạnh, điểm yếu. Nghiên cứu này là nghiên cứu hồi cứu đầu tiên tại Việt Nam có quy mô lớn bao gồm 10.870 NB phẫu thuâtt nhằm so sánh hiệu quả và độ an toàn của rivaroxaban với warfarin với thời gian theo dõi sau ra viện tới 3 tháng. Kết quả cho thây tính hiệu quả và an toàn của rivaroxaban vượt trội so với warfarin. Tuy nhiên để có bằng chứng tin cậy hơn, cần phải triển khai thêm các nghiên cứu tiến cứu, đa trung tâm, ngẫu nhiên có đối chứng trên quy mô lớn.

Ngoài ra, do hạn chế của thiết kế hồi cứu, nên đã không đánh giá sự tuân thủ thuốc của người bệnh tham gia nghiên cứu và không thể kiểm soát việc sử dụng các biện pháp dự phòng huyết khối cơ học sau khi xuất viện. Bền canh đó, nghiên cứu của chúng tôi mới chỉ phân tích thống kê cơ bản mà chưa có điều kiện ghép cặp những NB có đặc điểm tương đồng để chỉ ra rõ hiệu quả điều trị của rivaroxaban và warfarin trền từng nhóm NB.

\section{KẾT LUẬN}

Tỷ lệ NB điêuu trị dự phòng rivaroxaban sau phẫu thuật là $37 / 6679(0,6 \%)$ và NB điều trị warfarin $52 / 4191(1,2 \%)$. Sau ra viên 90 ngày có $36 / 6679(0,5 \%)$ NB dự phòng với rivaroxaban xuất hiện HKTM ít hơn 51/4191 (1,2\%) NB bệnh dự phòng với warfarin rõ rệt $(p<0,001)$

Tỷ lệ NB có biến chứng xuất huyết trong 2 nhóm sử dụng thuốc dự phòng khác nhau có ý nghĩa thống kê, với biến chứng xuất huyết ở nhóm dự phòng với warfarin nhiều hơn so với nhóm dư phòng với rivaroxaban $(7,3 \%$ và 4,2\%). Trong số biến chứng xuất huyết xuất hiện phần lớn là nhồi máu não $(3,7 \%$ trong nhóm dự phòng với rivaroxaban và $5.9 \%$ trong nhóm dự phòng với warfarin).

\section{TÀI LIẸU THAM KHẢO}

1. Fassiadis N (2011), "Rivaroxaban: direct factor Xa inhibition to treat acute deep vein thrombosis", $\mathrm{Br}$ ] Hosp Med, 72, 486.

2. Bui My Hanh, Hung Duong Duc, Nguyen Hoang Hiep Vinh Pham Quang và các cộng sự. (2019), "Frequency and risk factor of lower-limb Deep Vein Thrombosis After major orthopedic surgery in Viet Nam patients. ", Open Access Macedonian Journal of Medical Sciences, 7(24), 125-129.

3. Bố Y tế (2015), công văn $9324 / B Y T-B H ~ V / v$ trích xuất đầu ra dữ liếu yêu cầu thanh toán BHYT.

4. Thomas L. Ortel, Ignacio Neumann và Walter Ageno (2020), "American Society of Hematology 2020 guidelines for management of venous thromboembolism: treatment of deep vein thrombosis and pulmonary embolism", Blood Adv, 4, 4693-4738.

5. Yue Zou, Shaoqi Tian và Yuanhe Wang et al (2014), "Administering aspirin, rivaroxaban and low-molecular-weight heparin to prevent deep venous thrombosis after total knee arthroplasty ", Blood Coagul Fibrinolysis, 25(7), 660-4.

6. Kucher N, Aujesky D và Beer JH et al (2016), "Rivaroxaban for the treatment of venous thromboembolism. The SWIss Venous ThromboEmbolism Registry (SWIVTER).", Thromb Haemost, 116(3), 472-9.

7. Sean T Duggan (2012), "Rivaroxaban: a review of its use for the prophylaxis of venous thromboembolism after total hip or knee replacement surgery", Am J Cardiovasc Drugs, 12(1), 57-72.

8. Craig I C, Alexander $G$ G và Thomas J B (2018), "Effectiveness and Safety of Rivaroxaban Versus Warfarin in Frail Patients with Venous Thromboembolism", Am J Med, 131(8), 933-938. 